\title{
Cultura de bioseguridad en la gestión de servicios turísticos
}

\author{
Culture of Biosafety in tourism services management
}

Leonardo Antonio Prado Loza
jachaleon@gmail.com
Código ORCID: 0000-0002-6647-9953

Gateway Bolivia Consultores La Paz - Bolivia

La pandemia del COVID-19 exige el desarrollo de nuevas medidas que permitan reiniciar las operaciones turísticas en todo el mundo. Esta investigación tuvo como objetivo proponer una metodología para implementar la cultura de bioseguridad en los procedimientos cotidianos de la cadena de servucción turística de Bolivia. El estudio se desarrolló bajo un enfoque cualitativo de corte transversal que tuvo alcances exploratorio y descriptivo; para recoger información de organismos internacionales y representantes del turismo en Latinoamérica, se aplicaron las técnicas consulta a expertos y entrevistas a profundidad.

Como resultado se propuso una metodología para implementar la cultura de bioseguridad que permite brindar un servicio bioseguro, planificado y certificado, que articula cuatro elementos: liderazgo, diseño, ejecución y adaptabilidad. En conclusión, para trabajar en el sector se tendrá que cambiar la concepción del diseño del servicio, aprendiendo acerca de bioseguridad y cómo implementarla en el entorno del turismo.

Palabras clave: Servicio; Turismo; Bioseguridad; Pandemia; Cultura

\begin{abstract}
The COVID-19 pandemic requires the development of new measures to restart tourism operations around the world. This research aimed to propose a methodology to implement the biosafety culture in the daily procedures of the tourist service chain in Bolivia. The study was developed under a cross-sectional qualitative approach that had exploratory and descriptive scopes; To collect information from international organizations and representatives of tourism in Latin America, expert consultation techniques and in-depth interviews were applied.

As a result, a methodology was proposed to implement the biosafety culture that allows providing a biosecurity, planned and certified service, which articulates four elements: leadership, design, execution, and adaptability. In conclusion, to work in the sector, the conception of the service design will have to be changed, learning about biosafety and how to implement it in the tourism environment.
\end{abstract}

Key words: Service; Tourism; Biosafety; Pandemic; Culture 


\section{INTRODUCCIÓN}

La seguridad ha sido desde siempre inherente al desarrollo de la actividad turística; todo prestador de servicios turísticos tiene la responsabilidad de velar por proporcionar un servicio que logre satisfacer las expectativas de los turistas, ya sea en una excursión, una experiencia gastronómica, hospedera o en otro enclave de la cadena de servicios. Asimismo, está implícita la responsabilidad de salvaguardar la seguridad física de los involucrados. Pero la pandemia provocada por la COVID-19 (OMS, 2020a), ha hecho incursionar en el desarrollo e implementación de nuevas medidas que permitan reiniciar las operaciones turísticas en todo ámbito.

Aunque las realidades de gestión y los flujos de pasajeros difieren entre un país y otro; a la hora de enfrentar la nueva coyuntura, todos se encontraron en la misma situación, sin grandes diferencias respecto a las medidas sanitarias de cuarentena global, cierre de fronteras e inmovilización de pasajeros. Unos buscando soluciones estratégicas, otros enfocados más en la inmediatez de lo táctico, pero todos con la prisa de tener que cumplir con las cargas sociales, alquileres y otros costes fijos independientes a los flujos de turistas.

De ahí que se debe puntualizar en la implementación de la cultura de seguridad en operaciones turísticas y de atención al pasajero, pero de ahora en más, considerando como parte del paquete de seguridad a la bioseguridad como un componente que se haga habitual en la operatividad diaria y que permita, consecutivamente, reactivar las actividades sin poner en riesgo de contagio al personal de primera línea, ni a los turistas.

Por tanto, el objetivo de la investigación fue proponer una metodología para implementar la cultura de bioseguridad en los procedimientos cotidianos de la cadena de servucción turística. Con este propósito, se estudió el impacto de la pandemia de manera general en el contexto mundial y particularmente desde la perspectiva de Bolivia, un país en vías de desarrollo que tiene alta participación económica del sector turístico.

\section{METODOGÍA}

Se realizó un estudio cualitativo de corte transversal. En una primera instancia y a modo de diagnóstico se observó y describió los efectos de la pandemia en el sector turístico y sus implicaciones. Posteriormente, se propuso un soporte metodológico para implementar la cultura de bioseguridad en los procedimientos cotidianos de la cadena de servucción turística.

El trabajo tuvo alcances exploratorio y descriptivo e implicó una inmersión inicial en el campo en busca de una interpretación contextual. Con cierta flexibilidad investigativa, la recolección de datos sin medición numérica permitió responder a las preguntas: ¿Cuál será el impacto que está teniendo la COVID-19 en Bolivia y otros destinos del mundo?, ¿cuál es la situación de los subsectores por las medidas asumidas a raíz de la pandemia?, ¿qué medidas están implementando $\circ$ tienen pensado implementar en otros destinos y cuáles serían viables de aplicar en Bolivia?, ¿cuáles serían las medidas idóneas por adoptar de cara a una pronta reactivación del sector en Bolivia?

Para responder a estas preguntas, se utilizaron dos técnicas: consulta a expertos de organismos de promoción turística de Perú, Chile, Colombia, México y Brasil y a personeros de organismos internacionales; y finalmente, entrevistas a actores turísticos nacionales, 
autoridades y cabezas de diferentes subsectores turísticos.

La consulta a expertos tuvo como objetivos lograr un sondeo sobre el impacto de la cuarentena implementada en 2020, en la actividad turística. Para esto se contó con la participación de representantes de los órganos oficiales de promoción turística de Perú (PROMPERU), Chile (SENATUR), Colombia (PROCOLOMBIA), México (PROMEXICO) y Brasil (EMBRATUR), también se sostuvo conversación con organizaciones de gestión de turismo como la Travelife y el World Travel \& Tourism Council (WTTC), así como de la Cámara Nacional de Operadores de Turismo (CANOTUR), Asociación Boliviana de Agencias de Viaje y Turismo (ABAVYT), Federación Boliviana de Guías de Turismo (FEBOGUIT) y la Cámara Departamental de Empresarios Privados de Chuquisaca. La consulta estuvo estructurada en 3 ejes temáticos: Estado del sector o subsector; impactos percibidos en términos socioeconómicos y emocionales; y estrategias por seguir para lograr la reactivación del sector.

La información de fuentes primarias se recogió mediante video conferencias, las entrevistas se desarrollaron siguiendo un guion preconcebido para el efecto.

Para la revisión de fuentes secundarias, puesto que este evento no tenía precedentes, y por tanto no había investigaciones sobre el tema específico -manejo de pandemias globales- para el sector turismo, se revisaron investigaciones de epidemiología como las presentadas por Bhopal (2008) y por Perdomo \& Martínez (2010), y principalmente los sitios web tanto de la Organización Panamericana de la Salud (OPS, 2020), como de la Organización Mundial de la Salud (OMS, 2020) y se asistió a conferencias virtuales sobre posibles medidas de reactivación de lo que en su momento denominaron "medidas post-COVID 19" de la Organización Mundial del Turismo (OMT, 2020) y el World Travel \& Tourism Council (WTTC, 2020).

Los resultados se organizaron en 3 etapas: Análisis de los retos y perspectivas en la prestación de los servicios turísticos a nivel global; análisis de las necesidades de seguridad y bioseguridad de los servicios turísticos en Bolivia; y propuesta de una metodología para desarrollar cultura de bioseguridad turística en Bolivia.

RESULTADOS

\section{Retos y perspectivas en la prestación de los servicios turísticos}

Como resultado de la consulta a expertos en turismo a nivel nacional e internacional, se pudo conocer: la situación del sector o subsector; el impacto percibido en términos socioeconómicos $y$ emocionales; $y$ las propuestas de posibles soluciones. Según se detalla a continuación.

\section{Situación del sector}

En un momento sui generis, como fue el comienzo de la cuarentena rígida, existió cierta desorientación e incertidumbre sobre cómo afrontar las medidas impuestas; las operaciones aeroportuarias y de transporte terrestre se enfrentaron al cierre de fronteras; resultado en flujos turísticos paralizados a nivel global. Darle una lectura clara al devenir era incierto, algunos optimistas, como la EMBRATUR y SENATUR de Chile, daban 7 o 9 meses; los más pesimistas, entre ellos la PROMPERÚ, La Secretaría de Turismo (SECTUR) $y$ el Fondo Nacional de Fomento al Turismo (FONATUR) de México, PROCOLOMBIA y la 
propia OMT, vaticinaron un retorno a actividades de entre 12 a 15 meses, pero nadie anticipaba una segunda, tercera y hasta cuarta ola de contagios y nuevas sepas. En este estado de indefensión es que los planificadores y estrategas turísticos avizoraban, ya por distintos medios y de diversas maneras, una salida: la certificación de bioseguridad.

Desde ya el panorama pintaba números rojos para la economía del sector turístico mundial que tardaría en reactivarse más que con otro tipo de eventos, como ser problemas climáticos, disturbios sociales $\mathrm{O}$ crisis económicas. Esta vez se trató una realidad muy diferente a todo lo conocido hasta el momento y con efectos similares en cada subsector de la actividad turística, pero con consecuencias diversas a la vez. Los turoperadores gastronómicos, empresas hoteleras y guías, por mencionar algunos. Aunque forman una cadena de servicios que se complementa no recibieron de la misma forma los impactos de los cierres de fronteras, puesto que la inversión realizada en la planta turística varía de un subsector a otro así como cada modelo de negocio. La estrategia y los ajustes que se tengan que hacer para la reactivación de los subsectores serán diferentes; también en cuanto a tiempo, inversión y promoción.

Según informan los expertos nacionales, las cabezas de sector optaron por exigir al Estado su ayuda, pero la prioridad era una sola: Salud, por ello no se pudo contar con los subsidios y ayudas económicas que se solicitaron.

\section{Impacto percibido en términos} socioeconómicos y emocionales

La paralización del turismo tuvo como principal consecuencia el surgimiento de una crisis económica en el sector. Se estima que cerca de 100000 de los 400000 empleos directos e indirectos de los diferentes subsectores quedaron en latencia en Bolivia (Organización Internacional del Trabajo, 2021); se hizo urgente la necesidad de presentar alternativas de solución que respondan a las necesidades de los actores y empresarios turísticos, en cuanto a contar con herramientas que permitan reinsertarse ágilmente y con potencia en los mercados.

Los organismos, instituciones y expertos consultados entienden que, si bien no es una crisis estructural, para los prestadores de servicios turísticos significó en muchos casos el cierre definitivo de operaciones.

Asimismo, la percepción de algunos expertos internacionales reconoce como otro factor crítico el impacto psicológico y moral que se produjo en la mayoría de los subsectores; al respecto expresan que los más afectados fueron los guías, pues un guía profesional no tiene otra actividad económica; anímicamente éste fue uno de los subsectores más afectados directamente, si bien no tienen las pérdidas operativas de los turoperadores, gastrónomos u hoteleros (por cuanto hace a la inversión y costes fijos), su economía depende exclusivamente de los flujos turísticos para generar sus ingresos familiares.

\section{Propuestas de posibles soluciones}

Muchos de los organismos de promoción de países (SENATUR de Chile, PROMPERU de Perú y La Secretaría de Turismo SECTUR, el Fondo Nacional de Fomento al Turismo FONATUR de México, PROCOLOMBIA de Colombia y EMBRATUR de Brasil) coincidieron en formar a los empresarios turísticos en temas relacionados con bioseguridad, apostando cada uno por crear sellos de certificación de turismo bioseguro. Los primeros en brindar 
esta respuesta fueron los miembros de la Asociación Empresarial Hotelera de Madrid AEHM con su sello "Covid-19 free" (Hosteltur, 2020); en seguida salió la oferta del sello "Safe Travel" del Consejo Mundial de Viajes y Turismo (WTTC, 2020), organismo que en primera instancia fue europeo, pero luego amplió sus operaciones al resto del mundo. En un corto tiempo se desarrollaron sellos locales, parecidos en varias latitudes, teniendo el del WTTC un carácter global.

Los organismos de países siguieron una senda parecida, a modo de brindar un soporte para que pudiesen certificarse y así optar por reinsertarse en el mercado a la brevedad, luego de las medidas de pandemia. Para ello había que crear una manera de hacer e implementar y nadie la tenía, pues jamás se había hecho el ejercicio de conjugar medidas clínicas de bioseguridad y turismo. Es así como, en los países mencionados se comenzaron a dar talleres virtuales de bioseguridad turística por subsectores, que permitieran a los empresarios y actores estar listos para la vuelta a las actividades.

En Bolivia, en tanto que el clima político pre y post electoral se tornó más favorable hacia las políticas públicas en turismo, se consiguió en un esfuerzo coordinado con algunos municipios de vocación turística como Sorata, Uyuni y Coroico; realizar talleres de formación a los actores turísticos, logrando la emisión de un sello municipal de "turismo bioseguro" en cada caso.

Realizando visitas técnicas junto con personeros de la intendencia municipal para verificar la correcta implementación de los protocolos de bioseguridad en agencias, turoperadoras, hospedajes, gastrónomos y autoridades de tráfico y vialidad para los transportes turísticos. A fin de garantizar se realizaron talleres de formación de bioseguridad para los actores turísticos; en un esfuerzo coordinado con algunos municipios de vocación turística como Sorata, Uyuni y Coroico; logrando...

Con un proceso metodológico objetivo, que permita conseguir una respuesta útil operativa que no signifique grandes estipendios a los empresarios y que además les permita responder a las nuevas exigencias de los mercados internacionales, se trabajó en el desarrollo de un protocolo de bioseguridad adecuado a la realidad nacional; donde se plantea como piedra fundamental la cultura de bioseguridad. Se espera sea una ventaja comparativa y competitiva para el destino Bolivia en el nuevo contexto del mercado turístico mundial.

\section{Seguridad y bioseguridad de los servicios turísticos en Bolivia}

Según se constató en las entrevistas, está latente la necesidad de adoptar nuevas medidas de bioseguridad basadas en la experiencia previa de haber implementado por 10 años el Sistema de Calidad Turística en Bolivia. Este sistema incluye en su metodología la aplicación de manuales de buenas prácticas turísticas; con lineamientos, protocolos y procedimientos adecuados a cada área de la actividad, según sus realidades de gestión y requerimientos operativos.

En este sentido, se tomó en cuenta los criterios de los actores y se concluyó en que la respuesta es conseguir implementar medidas de bioseguridad al Sistema de Calidad Turística, de modo que Bolivia cuente con los medios para recibir turistas brindando normas de bioseguridad que les permitan disfrutar del destino sin inquietarse. En primera instancia se propone adecuar la oferta de servicios 
turísticos en mercados internos y regionales, y luego al mercado mundial.

Mediante el esquema presentado en la Figura 1, se plantea seguir la nueva interacción intersectorial que deviene orgánicamente de la necesidad de reactivar el sector turístico aplicando protocolos de bioseguridad.

\section{Figura 1.}

Esquema de actuación del sector turismo ante la pandemia de COVID-19 en Bolivia

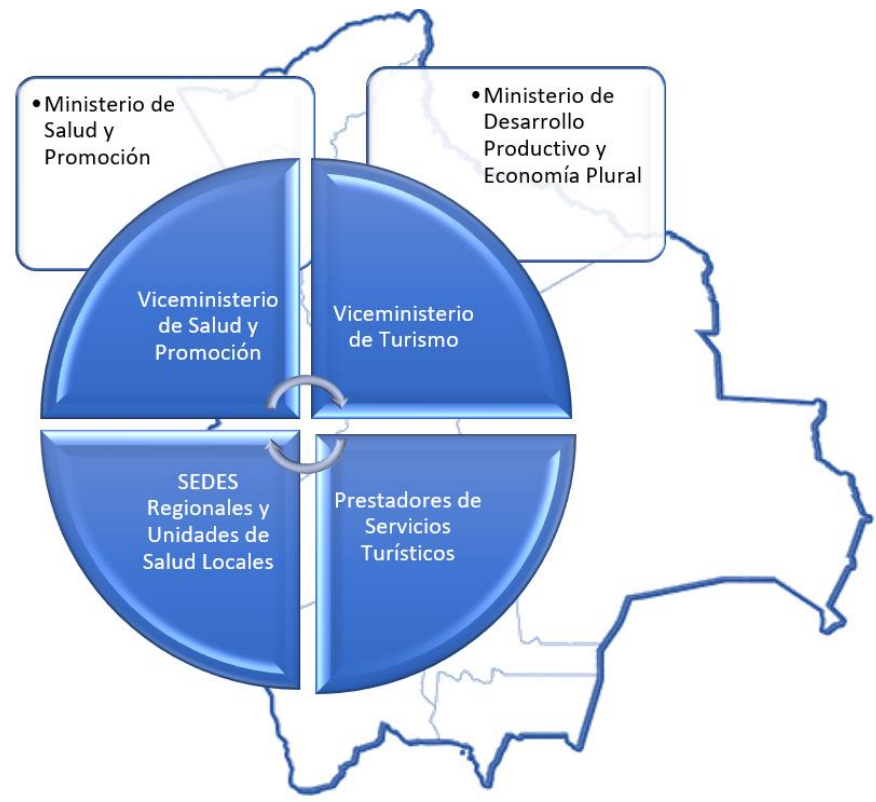

Fuente: Gateway Bolivia Consultores (2020)

En la Figura 1 se muestra la actuación del sector Turismo en Bolivia ante la pandemia de COVID-19, remarcando la participación de las instituciones involucradas y el nuevo nexo cooperativo que debe haber con el sector de salud en cada estamento, para que la operación garantice un esfuerzo coordinado que permita brindar servicios bioseguros, no sólo desde el sector privado, sino aunando esfuerzos en los servicios sanitarios; a través de la coordinación intersectorial que pasa por el nexo entre el Ministerio de Desarrollo Productivo y Economía Plural y el Ministerio de Salud y Promoción, que sirven de paraguas para las gestiones de los Viceministerios especializados, para finalmente aterrizar en el nivel operativo de prestación de servicios tanto de salud como de turismo.

\section{Metodología para desarrollar cultura de bioseguridad turística en Bolivia}

Cultivar la seguridad psicológica dentro de la cultura de un equipo de trabajo proporciona la base para generar apertura y confianza. Se propone sentar las bases de la metodología priorizando la seguridad psicológica, puesto que ésta proporciona beneficios en el lugar de trabajo que incluyen: reconocer los límites del conocimiento actual y mejorar la innovación del equipo; mejorar la probabilidad del éxito 
de la innovación de procesos; promover la escucha activa y el aprendizaje de todos los miembros; y aumentar la capacidad de aprender de los errores.

El buen manejo y el liderazgo en una organización proporcionan un circuito cerrado para la seguridad psicológica. Las dos acciones más esenciales identificadas para esta funcionalidad son: (1) gestión participativa y (2) gestión inclusiva. Estructura de equipo clara y relaciones sólidas de equipo son las características más propicias para la seguridad psicológica dentro de una empresa turística.

\section{Figura 2}

Peligro psicológico vs seguridad psicológica

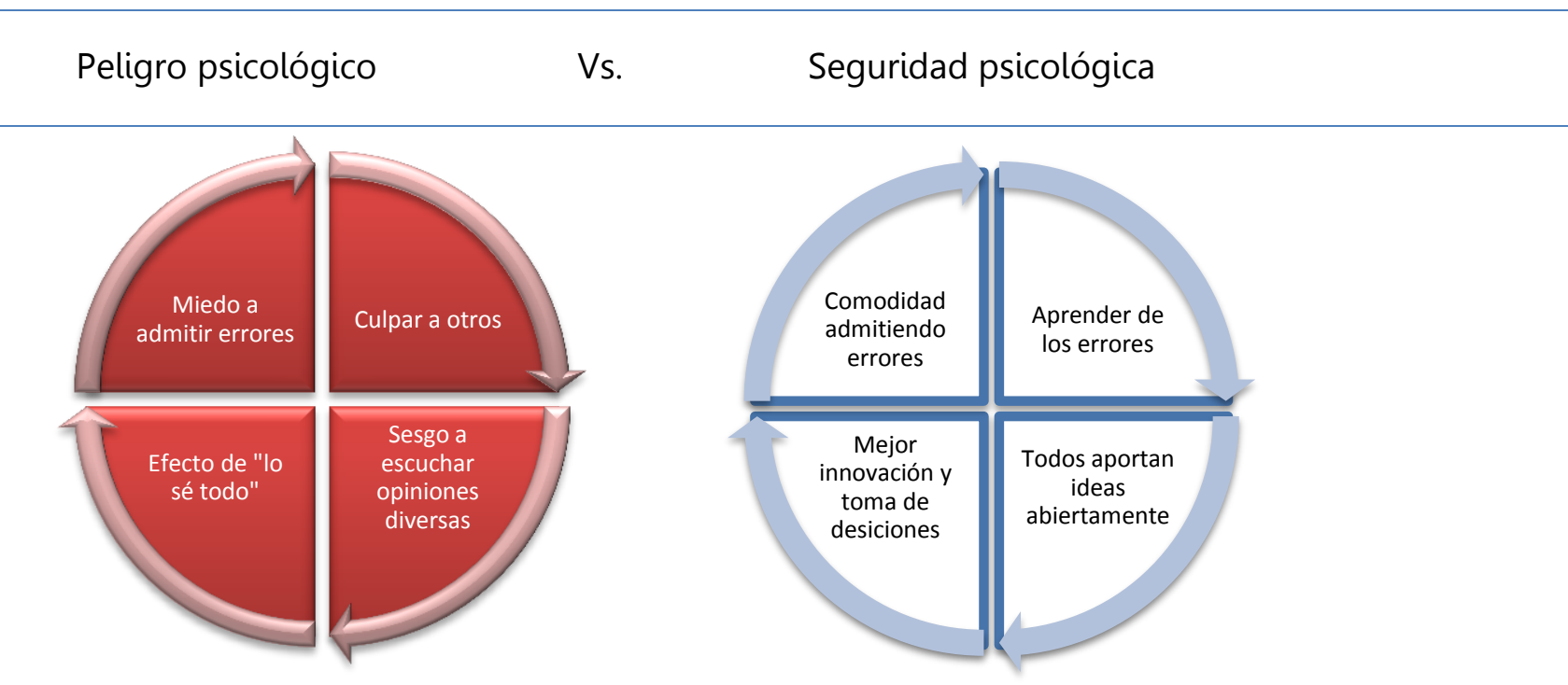

Fuente: Joseph (2016)

La Figura 2 muestra el aporte de Joseph (2016), en el lado izquierdo se observa una situación en la que el individuo siente peligro psicológico, que se caracteriza por: miedo a admitir errores, culpar a otros, efecto de "lo sé todo" y sesgo a escuchar opiniones diversas. En la parte derecha de la figura se ve una situación opuesta, en la que el individuo tiene seguridad psicológica y se desenvuelve de la siguiente manera: comodidad admitiendo errores, aprende de los errores, innovación, toma de decisiones y comodidad al aportar ideas abiertamente.

¿Qué tiene de especial o único la cultura de seguridad para los actores turísticos que trabajan en el terreno con turistas? El diagrama presentado en la Figura 3 ilustra algunos de los muchos factores que deben tenerse en cuenta al planificar trabajar en el sector turístico después de la COVID-19. 


\section{Figura 3}

Factores para considerar al trabajar en turismo

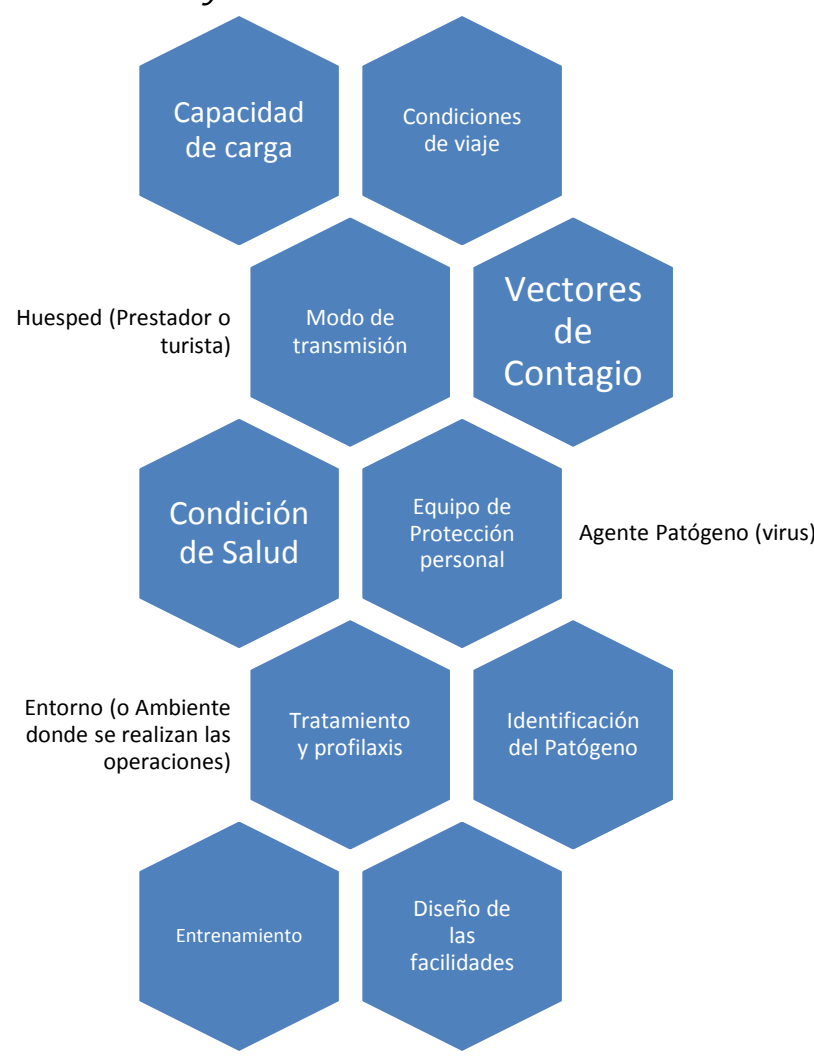

Al igual que cualquier actividad humana hay problemas únicos que deben considerarse al trabajar con personas, que incluyen: los virus no se consideran organismos vivos, son partículas infecciosas que consisten en cadenas de material genético ADN o RNA y una cápside con proteínas; no sobreviven por sí solos, ya que solo puede reproducirse dentro de las células de otros organismos, su efecto sobre el prestador $o$ el pasajero puede verse influenciado por la salud de este; se pueden propagar a través de numerosos mecanismos (gotitas, aerosoles, mucosas, orales, fecales, transmitidas por la sangre); y pueden insertarse en un genoma y tener efectos a largo plazo.

La Figura 3 presenta los factores a considerar al momento de realizar la planificación y logística en el proceso de servucción turística, considerando la amenaza latente del coronavirus de tipo 2 causante del síndrome respiratorio agudo severo (SRASCoV-2), y el uso de todos los elementos de bioseguridad que deben inmiscuirse de ahora en adelante para el desenvolvimiento de las actividades, minimizando riesgos.

Se espera que todos los miembros de la comunidad turística integren la seguridad en sus actividades, y vayan más allá del cumplimiento mínimo. Los elementos presentados en la Figura 4 procuran sentar las bases para construir y apoyar un entorno de servucción turística seguro 


\section{Figura 4}

Elementos de seguridad de la servucción turística

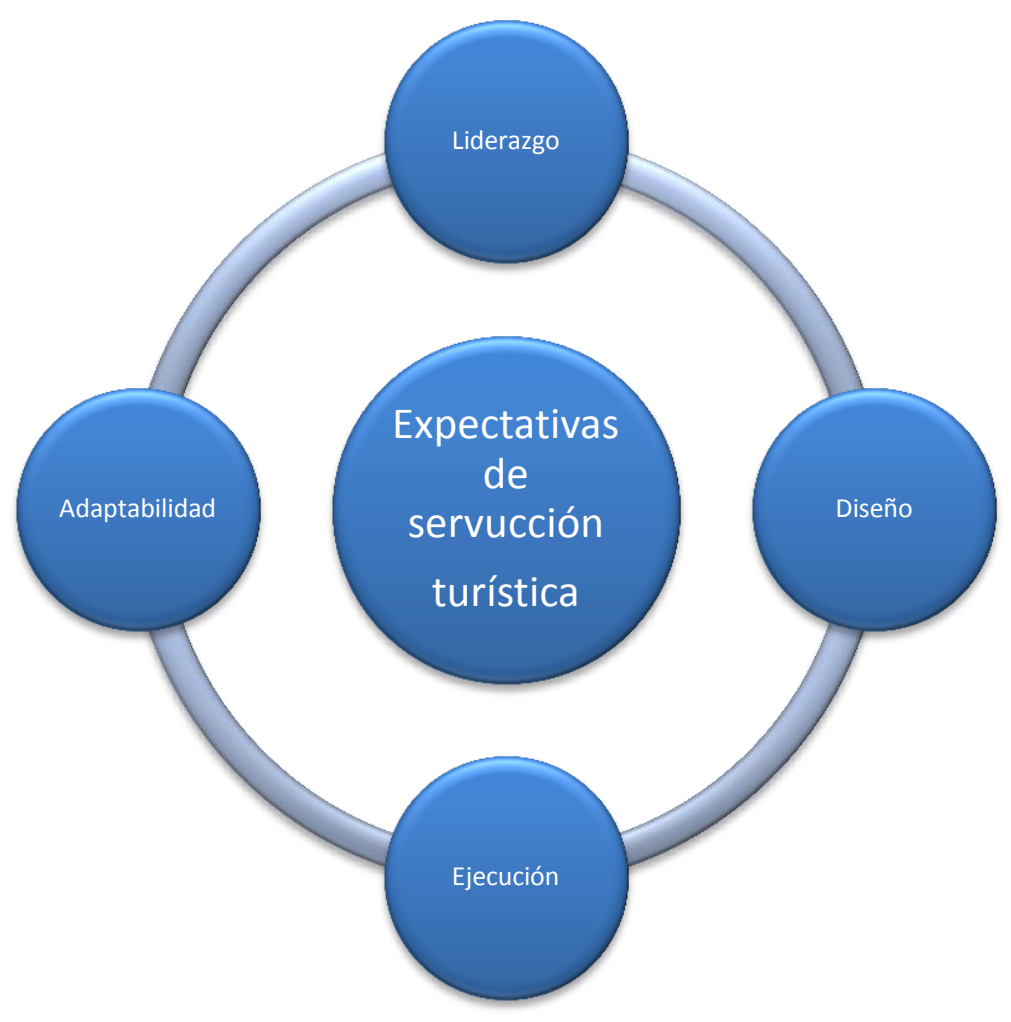

El elemento central de la Figura 4, expectativas de servucción turística, se refiere a las expectativas de los pasajeros respecto a un destino en particular; para alcanzar y superar estas expectativas es fundamental lograr la articulación del elemento central con los cuatro elementos que se muestran en la periferia de la figura: liderazgo, diseño, ejecución y adaptabilidad. Entonces, la prestación del servicio se da en un nivel óptimo bioseguro, planificado y certificado. Según se detalla a continuación.

\section{Liderazgo}

El concepto propuesto es "lidere con el ejemplo, cumpla con las reglas y esté dispuesto a hablar si ve prácticas inseguras". Se insta a la dirección/gerencia y a otros supervisores o jefes de área a incluir la seguridad en la agenda e incorporarla en sus valores y prácticas de prestación de servicio.

Este elemento implica un cambio de conducta en todos los miembros de las empresas del rubro turístico, que se traduce en: 1) Los miembros de la empresa tratan abiertamente preocupaciones de seguridad; 2) El director/gerente y los miembros del equipo gerencial mantienen un ambiente en el que el personal se siente libre de plantear inquietudes; 3) Las acciones confirman la seguridad como una prioridad que respalda y es compatible con un servicio turístico seguro; y 4) El ciclo de retroalimentación sobre cuestiones de seguridad (de abajo hacia arriba 
y de arriba hacia abajo) está cerrado (abordado) a nivel de gestión de empresa.

El líder deberá evaluar la delegación de funciones y responsabilidades, tomando en cuenta las complicaciones que ésta puede representar. A menudo hay dos problemas potenciales asociados con este acuerdo: 1 . La delegación implica responsabilidad, pero puede tener poca o ninguna autoridad o poder para hacer cumplir las prácticas; y 2. Las comunicaciones entre gerente y jefe de área pueden verse afectadas por numerosas demandas de tiempo de la gerencia. La atención plena a estos problemas ayuda a desarrollar y mantener un entorno de trabajo sólido y saludable. Algunos aspectos clave de la delegación efectiva incluyen hacer coincidir el nivel de habilidad correcto con la tarea, tener objetivos firmes y proporcionar un apoyo sólido.

\section{Diseño}

El concepto propuesto es "tómese el tiempo para evaluar sistemáticamente el riesgo y planificar los peligros identificados". El diseño del servicio debe adecuarse a las necesidades de bioseguridad, incorporando seguridad en los procedimientos de cada área de prestación de servicios, según las recomendaciones de los Manuales de Buenas Prácticas.

Este elemento requiere el compromiso del gerente o tomador de decisiones, quien debe comprender los riesgos de la prestación de servicios turísticos que se realiza. Su participación en el programa de bioseguridad permitirá la integración de la seguridad en la cultura de operación de la empresa.

\section{Ejecución}

El concepto propuesto es "tome medidas para controlar sus riesgos". Durante la ejecución de los servicios turísticos, el prestador del servicios deberá asegúrese de: tener el equipo de protección adecuado, de que los controles funcionan correctamente y las tripulaciones en el terreno (guías y choferes), los meseros, los cajeros, los caunteres, los recepcionistas, estén entrenando en seguridad para realizar su trabajo.

Los jefes de área deben hacer cumplir los controles establecidos en su sección. Este elemento implica tomar medidas de control de riesgo, según se detalla: 1. El gerente asegura que el personal, el equipo, las herramientas, los procedimientos y otros recursos necesarios para garantizar la seguridad en la prestación de servicios turísticos están disponibles; 2. Los miembros del equipo de trabajo de la empresa identifican y administran su propio entorno de seguridad y son receptivos y responsivos a las consultas y sugerencias sobre la seguridad del entorno de sus colegas; y 3 . El personal realiza su trabajo utilizando protocolos $y$ procedimientos consistentes con las mejores prácticas de seguridad en la empresa.

\section{Adaptabilidad}

El concepto propuesto es "La prestación de servicios turísticos no es un esfuerzo estático; la gestión de la seguridad requiere reevaluación, retroalimentación y refuerzo continuo".

Se deberá fomentar la presentación de informes por parte de los miembros de la organización, en los que se identifique, revise y analice las lecciones aprendidas, para después utilizarlas como oportunidades de enseñanza. Este análisis debe Involucrar todos los incidentes de trabajo y si los hubiera, accidentes de contagio. Las prácticas de adaptación quedan expuestas a continuación: 1. El gerente/administrador evalúa el estado de 
seguridad de la firma y sabe qué y cómo gestionar cambios para mejorar la seguridad en la misma; 2. El gerente/administrador y el grupo de trabajo apoyan un entorno de aprendizaje continuo en el que se buscan, comunican e implementan oportunidades para mejorar la seguridad; y 3 . Las discusiones sobre seguridad se vuelven parte de las reuniones regulares de equipo; se informan de manera oportuna los accidentes de contagio cercanos a la oficina/empresa, y los miembros del personal solicitan información de seguridad para evitar futuros contratiempos al comprender cómo y por qué suceden los eventos.

\section{DISCUSIÓN}

Si bien se está estudiando mucho este tema, nadie sabe a ciencia cierta cuál será el devenir de la pandemia que ha llevado al planeta a ponerse en cuarentena. Haciendo una analogía, como antes del 9/11 no existían controles en los aeropuertos y después del evento todo viajero se debe reportar con horas de antelación para pasar por varios filtros de control antiterrorista antes de abordar un vuelo; la nueva normalidad por pandemia implicará rediseños de servicios que cambiarán la forma de hacer turismo. La seguridad se considerará una prioridad operativa, debido a los beneficios que los procedimientos y actitudes reflexivos y seguros irán a aportar a la operación turística en todo su amplio espectro, desde las agencias y las turoperadoras, hasta los hoteles, guías, transportes y servicios periféricos.

La "cultura de seguridad" se ha convertido en la nueva necesidad, el enfoque del programa y el deseo de los ejecutivos globales, verbalizado en el a menudo expresado: ¡Necesitamos una cultura de seguridad! Sin embargo, la cultura de seguridad no es nueva. La solución no es intentar crearla, los gestores de turismo necesitan aplicar los nuevos protocolos de seguridad de manera sistemática, aunque esto implique rediseñar los servicios, es la única forma de proveer seguridad personal a los pasajeros.

Las prácticas de seguridad, las percepciones de riesgos y las técnicas de mitigación han sido y siempre serán parte de la conversación humana, probablemente más entre aquellos que tienen más éxito en navegar los riesgos de la vida y son capaces de pasar este conocimiento a sus descendientes. La seguridad es parte de cada cultura. Hasta cierto punto, todos tienen o están influenciados por múltiples culturas de seguridad.

Las culturas no son un programa; son la interconexión que explica por qué los esfuerzos funcionan o no, tienen éxito o fracasan. Los prestadores de servicios turísticos tienen atributos de seguridad, pero tradicionalmente se han dividido en pedazos, algunos más presentes que otros, algunos no totalmente reconocidos y otros simplemente ignorados. Se debe tener una Gestalt (molde, modelo, forma) de cultura de seguridad, un todo que se percibe como más que la suma de sus partes, que es una segunda naturaleza para todos los participantes, una que influirá en las decisiones individuales que se llevan a cabo cuando nadie está mirando, la parte más importante de realidad cultural, de seguridad o de otro tipo.

Para que esta transición tenga éxito, todos deben ser conscientes de los problemas, estar abiertos a sugerencias, comunicarse y trabajar juntos para cambiar creencias y comportamientos. No es fácil, pero tampoco imposible, ciertamente es factible y sobre todo muy gratificante. 
CONCLUSIONES

A raíz de la pandemia provocada por la COVID-19, desde hace un año atrás, se tuvo que reaprender la manera de prestar servicios turísticos, implementando a los protocolos de seguridad un componente de bioseguridad. Algo inédito en turoperaciones, pues conlleva un aspecto hasta ahora limitado exclusivamente a personal sanitario y de laboratorios. Entonces toca asumir que una nueva manera de ver y hacer se ha hecho parte del desenvolvimiento cotidiano, tanto personal como profesional, pues si bien se cuenta con colaboradores entrenados para atención al turista, jamás se había enfrentado una situación como esta. Es así como, buscando soluciones y realizando consultas a distintos actores tanto del medio nacional como internacional, se llegó a una conclusión similar por distintos medios: para seguir trabajando se tendrá que cambiar la oferta una vez más, aprendiendo acerca de bioseguridad y cómo implementarla en el entorno del turismo. En una carrera por hallar la solución al problema, se concibe que la única manera de seguir es dar fuerza a los sistemas de certificación en bioseguridad turística y para ello hace falta implementar protocolos de actuación que conjuguen turismo y bioseguridad.

La reactivación del turismo implica volver a operar con nuevos procedimientos y rediseños de servicios. Esto es algo que se aprende a hacer con cada cambio de tendencia y según los requerimientos de los mercados emisores; sin embargo, ahora ya no será por moda, será por salud. Se debe, una vez más, cambiar los paradigmas y las formas de trabajar para preservar la salud de los clientes y del personal; las reglas de juego han cambiado y todos los actores deben adapte al nuevo entorno. Es una postura común, asumida a nivel general: si bien el turismo es una de las actividades económicas más afectada por la pandemia, también es el más resiliente y por su alta adaptabilidad será una de las de mayor reactivación cuando se den las condiciones para retomar operaciones. Aplicar protocolos de bioseguridad será parte de toda prestación de servicios turísticos, ya sea en un museo, al realizar paseos, brindar hospedaje, turismo gastronómico, o al hacer turoperaciones.

Crear una metodología a contra reloj fue imperativo para generar un aporte que coadyuve a los actores turísticos en un momento de crisis. Este es el comienzo que marca el rumbo que deben seguir las organizaciones del sector.

\section{REFERENCIAS}

Bhopal, R. (2008). Concepts of Epidemiology. New York, USA: Oxford University Press. 2nd edition

Gateway Bolivia Consultores. (2020, abril 21). Protocolo de Bioseguriad Turística, Manual de Implementación. Nuestra Señora de La Paz, La Paz, Bolivia: libro digital

Joseph, L. (2016, abril 12). World Economic Forum. Retrieved from https://www.weforum.org/agenda/2016/04/ team-psychological-danger-work-

performance?utm_content=buffer32409\&ut m_medium $=$ social\&utm_source $=$ twitter.co m\&utm_campaign=buffer

OMS. (2020a, febrero 27). WHO. Retrieved from Naming the coronavirus disease (COVID19) and the virus that causes it: https://www.who.int/emergencies/diseases/ novel-coronavirus-2019/technicalguidance/naming-the-coronavirus-disease(covid-2019)-and-the-virus-that-causes-it

OMS. (2020b, abril 2). WHO. Retrieved from Consejos actualizados de la OMS para el transporte internacional en relación con el brote del nuevo coronavirus 2019-nCoV: 
https://www.who.int/ith/2019-

nCoV_advice_for_international_traffic/es/

OMT. (2020, abril 15). UNWTO. Retrieved from GUIAR LA RECUPERACIÓN DEL TURISMO: https://www.unwto.org/es/turismo-covid19

OPS. (2020, marzo 30). PAHO. Retrieved from Directrices provisionales de bioseguridad de laboratorio para el manejo y transporte de muestras asociadas al nuevo coronavirus
2019 (2019-nCoV), 28 de enero de 2020: https://iris.paho.org/handle/10665.2/51896

Perdomo, I. V., \& Martínez Calvo, S. (2010). Estrategia metodológica para evaluar competencias profesionales en especialistas de Higiene y Epidemiología. Revista cubana de salud pública, 36, 142-147

WTTC. (2020, abril 14). Turismo y la situación mundial, una perspectiva de la WTTC. webinar. Virtual 